\title{
Evaluation Of The Effect Of Different Surface Treatments, Aging And Enzymatic Degradation On Zirconia-Resin Micro-Shear Bond Strength
}

This article was published in the following Dove Press journal: Clinical, Cosmetic and Investigational Dentistry

\author{
Jihad Saade I \\ Hasan Skienhe \\ Hani F Ounsi (iD) ${ }^{2}$ \\ Jukka P Matinlinna (D) ${ }^{3}$ \\ Ziad Salameh ${ }^{4}$ \\ 'Department of Prosthodontics, Faculty \\ of Dental Medicine, Lebanese University, \\ Beirut, Lebanon; ${ }^{2}$ Department of \\ Restorative Dentistry and Endodontics, \\ Faculty of Dental Medicine, Lebanese \\ University, Beirut, Lebanon; ${ }^{3}$ Department \\ of Restorative Dentistry and \\ Endodontics, Faculty of Dental Medicine, \\ Siena University, Siena, Italy; \\ ${ }^{4}$ Department of Dental Materials Science, \\ Faculty of Dentistry, University of Hong \\ Kong, Pokfulam, Hong Kong
}

Purpose: The purpose of this study was to evaluate the effect of surface treatments on zirconia-resin bonding and the effect of aging on bond durability for one year.

Method: Three hundred and twenty zirconia blocks were divided into 4 equal study groups. Group 1 (control): as-sintered, group 2: (GB): grit-blasted, group 3: (LAS): laser-etched, group 4: (SIE): selective infiltration etching. Composite cylinders were bonded to the zirconia with resin cement and ceramic primer. Aging was performed following 3 different aging protocols: thermocycling, storage in distilled water, or storage in an enzymatic esterase solution. Micro-shear bond strength test ( $\mu \mathrm{SBS})$ was recorded using a universal testing machine. $\mu$ SBS values were analyzed using twoway Analysis of Variance followed by Tukey post-hoc tests. Level of significance was set at 0.05 . Results: GB, LAS and SIE groups showed significantly higher values when compared to control. Groups GB, LAS and SIE reported a significant decrease up to $50 \%$ in $\mu$ SBS after water storage and enzymatic degradation, while control group reported a $90 \%$ decrease. Failure analysis showed mainly adhesive failure for control group, while the percentage of cohesive failure in resin cement was higher in SIE group compared to GB and LAS groups. Conclusion: Water aging and esterase solutions played a significant role by increasing bond degradation. A minimum of one-year water and esterase storage medium should be used to evaluate the durability of the bond between resin cement and zirconia.

Keywords: air abrasion, laser, MDP primer, resin cement, aging

\section{Introduction}

The advancement of digital dentistry has expanded applications of zirconia in prosthetic dentistry. ${ }^{1}$ The superior mechanical and esthetic properties combined with biocompatibility ${ }^{2}$ make zirconia the best substitute for ceramic fused to metal restorations. ${ }^{3}$ However, the adhesive bond to zirconia is questionable in some clinical situations, such as short abutment, compromised retention, and resin-bonded fixed partial dentures. ${ }^{4}$ This is related to the silicafree composition that characterizes zirconia as an acid-resistant material and renders hydrofluoric acid etching used on silica-based ceramics ineffective on zirconia.,

Different roughening techniques are suggested to promote adequate retention between resin cements and zirconia. The most common is grit-blasting with aluminum oxide $\left(\mathrm{Al}_{2} \mathrm{O}_{3}\right)$ particles using different particle shapes and sizes, and different abrasive times and pressures. ${ }^{7,8}$ Grit-blasting produces a micro-roughened zirconia surface that enhances the adhesive bonding by increasing surface energy, wettability and surface area. ${ }^{9}$ However, the stress exerted by grit-blasting may lead to cracks on the zirconia surface and further induce tetragonal to monoclinic phase transformation. The volume expansion of the transformed
Correspondence: Jihad Saade Faculty of Dental Medicine, Lebanese University, Beirut, Lebanon

Tel +961 3763404

Email jihadsaade00@gmail.com 
grains induces compressive stresses at the crack tip thus preventing crack propagation with an increase in mechanical strength. This phenomenon is known to as transformation toughening ${ }^{10}$ but on the other hand, excessive amounts of transformed grains tend to decrease mechanical strength ${ }^{11}$ and may affect the long-term performance of zirconia restorations. ${ }^{12,13}$

Alternative techniques for zirconia surface conditioning have been introduced such as grit-blasting before sintering, ${ }^{8}$ selective infiltration-etching technique, tribochemical silica coating, ${ }^{15}$ plasma spraying, ${ }^{16}$ surface fluorination, ${ }^{17}$ laser treatments, ${ }^{18}$ and silica coating. ${ }^{19}$ Silica coating provides a siliconized zirconia surface that can chemically interact with the applied silane to increase the adhesive bond to resin cements. $^{20}$ The durability of adhesive bonding to zirconia restorations relies on the mechanical and chemical surface treatment modalities. ${ }^{21}$ Studies have shown that chemical bonding between resin cements and zirconia surfaces could be achieved by using a primer and a resin cement based on adhesive monomer containing 10-methacryloyloxydecyl dihydrogen phosphate (MDP) acting as a coupling agent. ${ }^{22,23}$ However, despite the fact that grit-blasting could affect the final performance of zirconia restoration when subjected to oral stresses, ${ }^{2,24,25}$ the use of laser as an alternative surface treatment method is now of interest and is reported in numerous studies. ${ }^{26,27} \mathrm{Nd}-$ YAG laser surface treatments have shown increased surface roughness, wettability and bond strength to resin cement, ${ }^{28}$ but due to the different laser types and different parameters used, these studies have shown variable results regarding bond strength. ${ }^{29}$

Another important factor affecting the clinical performance of a restoration is aging. Oral mechanical stresses, temperature, and humidity have a great influence on bond degradation of zirconia restorations. ${ }^{21,25}$ In several studies, thermo-cycling and varying times of water-storage have been used as an artificial ageing method. ${ }^{30-33}$

The aims of this study were to evaluate 1)- different zirconia surface treatments and their effect on micro-shear bond strength of resin to zirconia and 2)- the effect of aging on the resin-zirconia interface. The null hypotheses tested were that there was no significant difference between the different surface treatments evaluated, and there was no significant decrease of the initial microshear bond strength values after different aging methods.

\section{Materials And Methods}

\section{Sample Preparations}

A total of 320 pre-sintered quadrangles were cut out of zirconia blocks (Amman Girrbach, Koblach, Austria) with the dimensions of $10 \times 10 \times 3$ using a low-speed diamond saw (Buehler, Lake Buff, WI, USA) under running tap water. Specimens were polished with silicon carbide grit paper \#400 (Grit flex, Italy) using a polishing machine (Buehler, Lake Buff, WI, USA) for surface standardization, ${ }^{34}$ and then subjected to oil-free high-pressure airflow for $1 \mathrm{~min}$. Samples were then sintered in a sintering furnace (Ceramil Therm, Amman Girrbach, Austria) according to manufacturer's instructions.

\section{Surface Treatment Protocols}

Samples were randomly divided into 4 study groups $(n=80)$ according to the surface treatment performed. Group 1 (control): as-sintered; group 2 (GB): the surfaces of sintered samples were grit-blasted with $50 \mu \mathrm{m}$ alumina particles (Vacumat 300, Vita Zahnfabrik, Germany) for $15 \mathrm{~s}$ under 3.5 bars pressure at a working distance of $10 \mathrm{~mm}$; group 3 (LAS): surfaces were etched using Er,Cr:YSGG laser (Waterlase MD system, Biolase, San Clemente, CA, USA) for $2 \mathrm{mins}(5.5 \mathrm{~W}$ power, $20 \mathrm{~Hz}$ with $100 \mathrm{~mJ}$ energy). ${ }^{35}$ A custom-made computerized robot was used to standardize the application of laser (Figure 1); ${ }^{36}$ group 4 (SIE): surfaces were subjected to selective infiltration etching (SIE) technique. ${ }^{14}$ After sintering, the surface of the specimens was abraded by a sequence of grit papers $\neq$ 200-800. A thin layer of low-fusing melting glass was applied on the zirconia surface. The specimens were then heated to $750^{\circ} \mathrm{C}$ for $2 \mathrm{mins}$, cooled to $650^{\circ}$ $\mathrm{C}$ for $1 \mathrm{~min}$, reheated to $750^{\circ} \mathrm{C}$ for an additional $1 \mathrm{~min}$, and then cooled to room temperature. The specimens were immersed in a bath of $9 \%$ hydrofluoric acid for 20 mins, and then every specimen was subjected to a high stream of air and water for 2 mins. All samples were cleaned using an ultrasonic device for $10 \mathrm{mins}$ and left to dry at room temperature for $24 \mathrm{hrs}$ before bonding.

\section{Composite Cylinders Preparation And}

\section{Cementation}

A total of 320 resin composite cylinders $(2 \mathrm{~mm}$ diameter and $2 \mathrm{~mm}$ height) were prepared by packing the resin composite (Z250, 3M ESPE, Saint Paul, MN, USA) into a Plexiglas mold. $4 \mathrm{~mm}$ Plexiglas slabs was placed on the surface and the bottom of composite to ensure a flat surface and to prevent the oxygen 

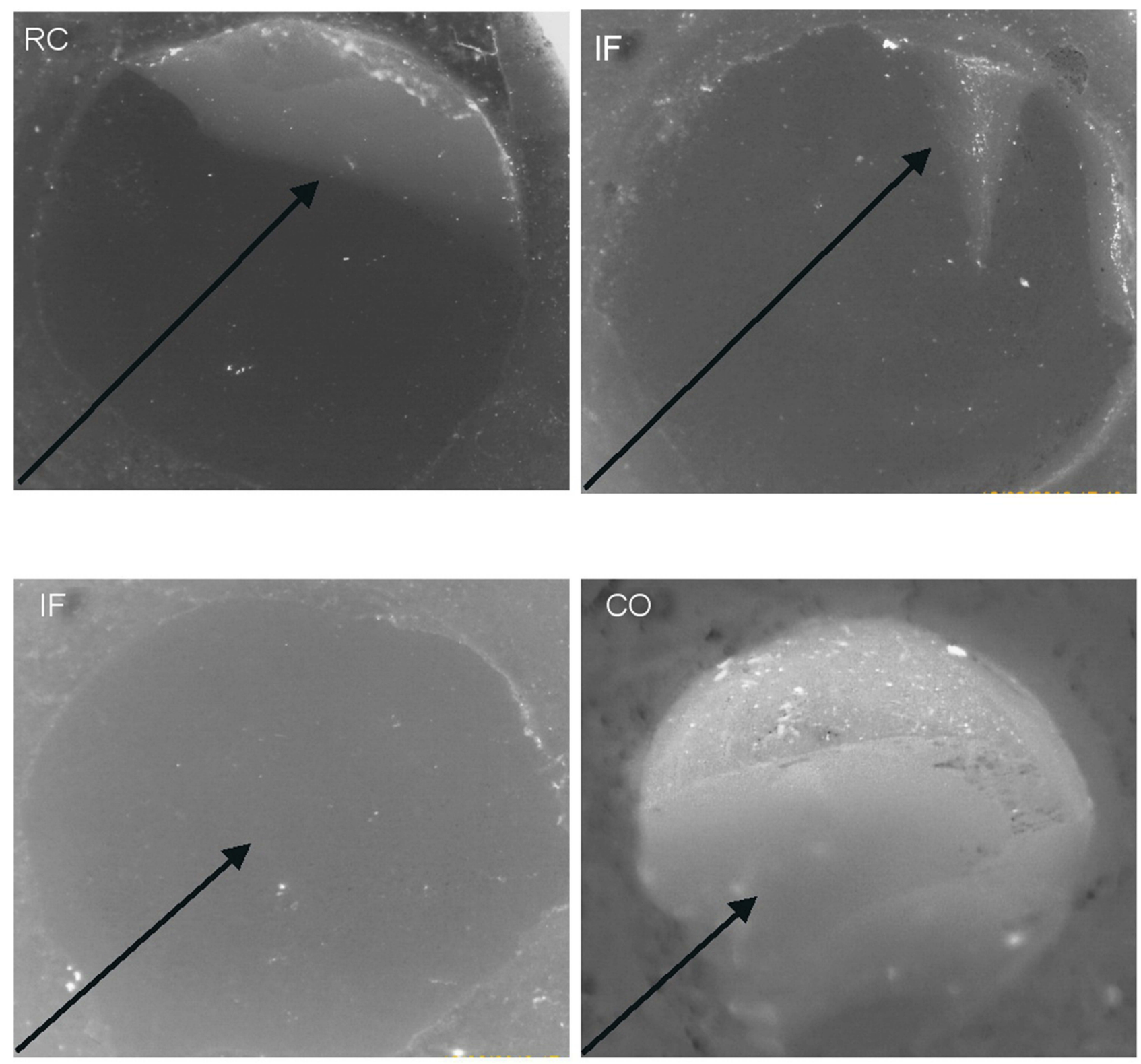

Figure I Failure modes of the studied groups: Cohesive failure (RC) within the resin cement; a part of resin cement adhered to zirconia surface (black arrow). Interfacial failure (IF) between the cement and zirconia; a little or no resin cement adhered on the zirconia surface ( black arrow). Cohesive within the resin composite (CO); the fracture with the composite cylinder (back arrow).

inhibition layer. Light-curing was done for 40 s from the top and 40s from the bottom (Elipar Free Light 2 LED, 3M-Espe, wave length 430-480nm, light intensity $1000 \mathrm{Mw} / \mathrm{cm}^{2}$, Saint Paul, Minnesota, USA). A primer (Clearfil Ceramic Primer, Kuraray, Tokyo, Japan) containing MDP was applied on the zirconia surfaces and left to dry for the 20s. The composite micro-discs were bonded to the treated zirconia surface using a dual-cure resin cement (Panavia F2.0, Kuraray Dental, Tokyo) under a fixed load of $450 \mathrm{~g}$. Excess cement was removed gently using a curette and microbrush, and cement was light-cured from 2 lateral sides and the top for 40 s each using the same light-curing device.

\section{Aging}

The 80 specimens in each group were then divided into 8 sub-groups $(\mathrm{n}=10)$ according to the aging treatments: Sub-group 1 (control): no any aging performed, subgroup 2 was tested after thermocycling $\left(5^{\circ} \mathrm{C}-55^{\circ} \mathrm{C}\right.$, 
Table I Mean In MPa And Standard Deviation (values) Of $\mu$ SBS Of Tested Groups Subjected To Different Surface Treatments And Aging

\begin{tabular}{|c|c|c|c|c|c|c|c|c|}
\hline \multirow[t]{2}{*}{ Groups } & Control & TCL & \multicolumn{3}{|l|}{ Water } & \multicolumn{3}{|l|}{ Esterase } \\
\hline & \multicolumn{2}{|l|}{ No storage } & 2 Weeks & 24 Weeks & 48 Weeks & 2 weeks & 24 Weeks & 48 Weeks \\
\hline Control & $10.4(7.2)^{\mathrm{a}, \mathrm{A}}$ & $6.2(3.1)^{\mathrm{b}, \mathrm{A}}$ & $6.8(3.7)^{\mathrm{b}, \mathrm{A}}$ & $2.6(2.9)^{\mathrm{c}, \mathrm{A}}$ & $0.2(0.7)^{\mathrm{d}, \mathrm{A}}$ & $9.4(3.6)^{\mathrm{a}, \mathrm{A}}$ & $4.3(1.6)^{\mathrm{b}, \mathrm{A}}$ & $1.2(0.4)^{c, d, ~ A ~}$ \\
\hline GB & $28.3(3.2)^{\mathrm{a}, \mathrm{B}}$ & $24.4(3.4)^{a, B}$ & $25.2(5.4)^{\mathrm{a}, \mathrm{B}}$ & $20.7(5.9)^{\text {a, b, B, C }}$ & $17.3(4.2)^{\mathrm{b}, \mathrm{B}}$ & $21.1(7.6)^{b, c, B}$ & I7.5 $(4.4)^{\text {b, c, B }}$ & I3.2(3.9) \\
\hline LAS & $25.9(3.8)^{\mathrm{a}, \mathrm{B}}$ & $22.3(3.6)^{a, B}$ & $20.5(4.3)^{\mathrm{a}, \mathrm{B}}$ & I $4.8(4.7)^{\text {b, B }}$ & I $4.8(4.7)^{\mathrm{b}, \mathrm{B}}$ & $21.1(3.7)^{\mathrm{a}, \mathrm{B}}$ & $15.0(4.2)^{\mathrm{b}, \mathrm{B}}$ & $11.8(3.4)^{c, B}$ \\
\hline SIE & $36(4.3)^{\mathrm{a}, \mathrm{C}}$ & $32(4.2)^{\mathrm{a}, \mathrm{c}}$ & $30.2(8.9)^{\mathrm{a}, \mathrm{C}}$ & $28.2(8.1)^{a, C}$ & $22.9(8.3)^{\mathrm{b}, \mathrm{B}}$ & $34.6(4.1)^{\mathrm{a}, \mathrm{C}}$ & $30.7(4.7)^{\mathrm{a}, \mathrm{C}}$ & $24.2(8.2)^{b, c}$ \\
\hline
\end{tabular}

Notes: Similar small superscripts indicate no significant difference between storage media for the same surface treatment (horizontal comparison). Similar capital superscripts indicate no statistical significance between the surface treatments (vertical comparison).

20sec dwelling time, 10,000 cycles), sub-groups 3, 4 and 5 were tested after storage in distilled water for 2, 24 and 48 weeks, respectively, sub-groups 6,7 and 8 were tested after storage in a prepared 0.1 unit $/ \mathrm{mL}$ enzymatic esterase solution $^{37}$ for 2,24 and 48 weeks, respectively (Table1).

\section{Microshear Bond Strength Test}

The microshear bond strength test ( $\mu$ SBS) was performed using a custom-made uni-bevel semi-circle chisel-shaped indenter mounted on a universal testing machine (YL-UTM Main, YLE GmBH, Bad Koenig, Germany) at a crosshead speed of $0.5 \mathrm{~mm} / \mathrm{min}$ until failure. The resin to zirconia shear bond strength values was obtained by dividing the load of failure by the bonded area.

\section{Failure Mode Analysis}

After $\mu$ SBS testing, zirconia surfaces were examined under optical microscope at $\times 20$ magnification $(\mathrm{BH}-2$, Olympus, Tokyo, Japan). Failure modes were classified as an interfacial failure (IF) where the crack traveled at the zirconia-resin cement interface with consideration of the area of crack origin, a cohesive failure (RC) in the resin cement where the crack originated outside the bonded interface and cohesive within the resin composite (CO) (Figure 1). ${ }^{37}$ The percentage of failures based on failure modes (IF, RC, and CO) are shown in Table 2.

\section{Statistical Analysis}

The data were analyzed using a statistical software package (SPSS version 23, Armonk, NY, USA). After normality and homosexuality confirmation, two-way Analysis of Variance was conducted followed by Tukey post hoc tests for multiple comparisons. The level of significance was set at 0.05 .

\section{Results}

The data reported in Table 1 show a significant effect of surface treatments $(\mathrm{p}<0.05, \mathrm{~F}=142.3)$, as well as aging and enzymatic degradation $(\mathrm{p}<0.05, \mathrm{~F}=43.8)$ on zirconia-resin bond strength $(\mathrm{p}<0.05, \mathrm{~F}=5.6)$. GB, LAS, and SIE groups displayed significantly higher bond strength compared to

Table 2 Failure Type And Percentage Of Fracture Of Zirconia And Resin Composite Discs

\begin{tabular}{|c|c|c|c|c|c|c|c|c|}
\hline \multirow[t]{2}{*}{ Groups } & Control & TCL & \multicolumn{3}{|l|}{ Water } & \multicolumn{3}{|l|}{ Esterase } \\
\hline & \multicolumn{2}{|c|}{ No Storage } & 2 Weeks & 24 Weeks & 48 Weeks & 2 Weeks & 24 Weeks & 48 Weeks \\
\hline CON & IF I00\% & IF $100 \%$ & IF $100 \%$ & IF $100 \%$ & IF $100 \%$ & IF I00\% & IF I00\% & IF $100 \%$ \\
\hline GB & $\begin{array}{l}\text { IF } 60 \% \\
\text { RC } 40 \%\end{array}$ & $\begin{array}{l}\text { IF } 70 \% \\
\text { RC } 30 \%\end{array}$ & $\begin{array}{l}\text { IF } 80 \% \\
\text { RC } 20 \%\end{array}$ & $\begin{array}{l}\text { IF } 90 \% \\
\text { RC I0\% }\end{array}$ & IF $100 \%$ & $\begin{array}{l}\text { IF } 90 \% \\
\text { RC I0\% }\end{array}$ & IF 100\% & IF $100 \%$ \\
\hline LAS & $\begin{array}{l}\text { IF } 70 \% \\
\text { RC } 30 \%\end{array}$ & $\begin{array}{l}\text { IF } 80 \% \\
\text { RC } 20 \%\end{array}$ & $\begin{array}{l}\text { IF } 80 \% \\
\text { RC } 20 \%\end{array}$ & IF $100 \%$ & IF $100 \%$ & $\begin{array}{l}\text { IF } 80 \% \\
\text { RC } 20 \%\end{array}$ & IF 100\% & IF $100 \%$ \\
\hline SIE & $\begin{array}{l}\text { IF } 20 \% \\
\text { RC } 30 \% \\
\text { CO } 50 \%\end{array}$ & $\begin{array}{l}\text { IF } 30 \% \\
\text { RC } 30 \% \\
\text { CO } 40 \%\end{array}$ & $\begin{array}{l}\text { IF } 40 \% \\
\text { RC } 40 \% \\
\text { CO } 20 \%\end{array}$ & $\begin{array}{l}\text { IF } 60 \% \\
\text { RC } 40 \%\end{array}$ & $\begin{array}{l}\text { IF } 70 \% \\
\text { RC } 30 \%\end{array}$ & $\begin{array}{l}\text { IF } 50 \% \\
\text { RC } 40 \% \\
\text { CO } 10 \%\end{array}$ & $\begin{array}{l}\text { IF } 80 \% \\
\text { RC } 20 \%\end{array}$ & $\begin{array}{l}\text { IF } 90 \% \\
\text { RC } 10 \%\end{array}$ \\
\hline
\end{tabular}

Abbreviations: IF, interfacial; RC, cohesive in resin cement; $\mathrm{CO}$, cohesive in resin composite. 
the control group. Groups that received surface treatment reported a significant reduction up to $50 \%$ in bond strength when subjected to thermocycling, water storage and enzymatic degradation as compared to $90 \%$ decrease of bond strength that was reported in the no surface treatment group. GB and LAS groups displayed a significant difference at 24 and 48 weeks of water storage, and significant differences were reported between the SIE group and all other groups at different storage times (Table 1). A significant decrease in bond strength was noted in GB and LAS groups at 48 weeks of water and esterase storage while SIE group was the least affected by aging.

Failure mode analysis showed complete interfacial failure for the control group, while the percentage of cohesive failure in resin cement was higher in SIE group compared to GB and LAS groups. At 48 weeks, GB and LAS groups reported a complete interfacial failure while SIE group showed the highest interfacial percentage failure at 48 weeks in esterase storage (Table 2).

\section{Discussion}

Different zirconia surface treatments were investigated in the present study to optimize the surface for micromechanical and chemical interaction with the adhesive system. Since the initial $\mu$ SBS values of experimental groups were significantly higher than the control, the first null hypothesis had to be rejected. The surface treatment of the samples was required to improve the mechanical interaction with the resin cement. ${ }^{38}$ Ozcan et al, ${ }^{39}$ stated that MDP monomer bonded directly to metal oxides, and that the hydroxyl group in MDP monomer reacted with the hydroxyl group on the zirconia surface. Nevertheless, Yi et $\mathrm{al}^{40}$ reported that the amount and flow of functional monomer alone were not sufficient to increase the zirconia adhesion ability without any surface pretreatment. In the same manner, several authors ${ }^{41-43}$ confirmed that the durable bond to zirconia ceramic could not be achieved with MDP containing cement without surface treatment.

The thermal stresses and humid environment inside the oral cavity may exhibit subcritical crack growth and hydrolysis of the resin at the bonded interface. ${ }^{44}$ Many studies ${ }^{45-47}$ used a combination of thermal cycling and water storage to test the resin bond durability; nevertheless, the best aging method remains a controversial topic. Hallmann et al, ${ }^{45}$ stated that water storage with additional thermocycling did not decrease bond strength value, whereas Heikkinen ${ }^{46}$ and Qeblawi et $\mathrm{al}^{47}$ concluded that the combination of water storage and thermocycling decreased bond strength values significantly. In this study, thermocycling and water storage were investigated in different combinations in an attempt to evaluate the most effective aging method. ${ }^{31,48,49}$ The $\mu$ SBS values obtained were significantly different after each aging method. The use of 10,000 thermocycles showed no significant decrease of $\mu$ SBS values in any group except for the control group. The failure mode of the control group showed a $100 \%$ interfacial failure, whereas the mode failure percentage of other groups showed no difference. Water storage, however, appeared to be more influential when it comes to evaluate bond degradation since the results showed that $\mu$ SBS values of all groups declined significantly after 6 months with another significant decrease after 12 months of water storage. As well as, the interfacial failure became $90 \%$ after 6 months and $100 \%$ after 12 months for GB and LAS groups and 70\% for SIE group.

The present results are in accordance with Aboushelib et al, ${ }^{50}$ who reported that the initial bond strength was not stable after water storage for 3 months, and with Oyagüe et $\mathrm{al}^{51}$ who concluded that water storage for 6 months played an important role in zirconia resin bond deterioration. Since human saliva has a greater ability than water to degrade resin. ${ }^{52}$ Esterase solution was used in this study as a storage medium to improve extrapolation of the results to the clinics, despite the fact that it was used as a contamination medium in other studies ${ }^{53-55}$ Our results showed a significant decrease of $\mu$ SBS values at 6 months of esterase storage and another significant drop after 12 months. The only surface treatment that preserved a high bond value was SIE. The interfacial failure of GB and LAS groups was $100 \%$ after 6 and 12 months, and $90 \%$ for SIE group after 12 months. The present results accord with a recent study by Aboushelib et al, ${ }^{56}$ that concluded that groups treated by alumina and laser had their $\mu$ SBS values reduced by $50 \%$ after 12 months of esterase storage whereas the best results were for the groups stored in artificial saliva with minor decrease in bond over the same period. This may reveal that the achieved bond for GB and LAS groups did not resist the water and esterase hydrolysis, even with the use of phosphate monomer as an adhesive promoter.

Many studies stated that the MDP monomer reduced the hydrolysis of bond, ${ }^{21,45,57,58}$ as it prevents the hydrolytic effect of the cement layer through the bonded margin. ${ }^{59}$ However, other studies that used MDP 
monomer stated that the bond did degrade after a period of water storage and thermocycling. ${ }^{46,47,51}$

Based on the results of the present study, we can conclude that there is no one factor responsible for bond degradation. The $\mu$ SBS values obtained during an experiment are a direct function of the combination of: 1- A suitable surface treatment method and the use of and MDP-based primer (that will dictate the quality of the resin-zirconia bond), and 2- The type of aging treatment used is paramount for the validity of in-vitro testing. It is noteworthy that thermocycling at 10,000 cycles did not degrade the bond. Further research using higher cycles values should be done to prove or disprove the effect of thermocycling on $\mu$ SBS values. 3-A minimum of one year in storage medium should be used during aging tests. Further studies should be performed to confirm that fact.

\section{Conclusions}

Within the limitation of this study the following conclusions may be drawn:

1. The primer used can lead to a sufficient adhesion between zirconia and resin cement.

2. A minimum of one-year water and esterase storage medium should be used to evaluate the durability of bond between resin cement and zirconia.

3. Water aging and esterase solutions played a significant role by increasing bond degradation

\section{Disclosure}

The authors report no conflicts of interest in this work.

\section{References}

1. Kelly JR, Bennett P. Ceramic materials in dentistry: historical evolution and current practice. Aust Dent J. 2011;1:84-96. doi:10.1111/ j.1834-7819.2010.01299.x

2. Denry I, Kelly JR. State of the art of zirconia for dental applications. Dent Mater. 2008;24:299-307. doi:10.1016/j.dental.2007.05.007

3. Daou EE. Esthetic prosthetic restorations: reliability and effects on antagonist dentition. Open Dent J. 2015;9:473-481. doi:10.2174/ 1874210601509010473

4. Schley JS, Heussen N, Reich S, Fischer J, Haselhuhn K, Wolfart S. Survival probability of zirconia-based fixed dental prostheses up to $5 \mathrm{yr}$ : a systematic review of the literature. Eur J Oral Sci. 2010;118:443-450. doi:10.1111/j.1600-0722.2010.00767.x

5. Papia E, Larsson C, Du Toit M, Vult von Steyern P. Bonding between oxide ceramics and adhesive cement systems: a systematic review. $J$ Biomed Mater Res B Appl Biomater. 2014;102:395-413. doi:10.1002/ jbm.b.33013
6. Kern M, Sasse M. Ten-year survival of anterior all-ceramic resinbonded fixed dental prostheses. J Adhes Dent. 2011;13:407-410. doi:10.3290/j.jad.a22096

7. Moon JE, Kim SH, Lee JB, Han JS, Yeo IS, Ha SR. Effects of airborne-particle abrasion protocol choice on the shear bond strength of resin cement. Ceram Int. 2016;42:1552-1562. doi:10.1016/j. ceramint.2015.09.104

8. Skienhe H, Habchi R, Ounsi H, Ferrari M, Salameh Z. Evaluation of the effect of different types of abrasive surface treatment before and after zirconia sintering on its structural composition and bond strength with resin cement. Biomed Res Int. 2018;27:2018.

9. Mahmoodi N, Hooshmand T, Heidari S, Khoshro K. Effect of sandblasting, silica coating, and laser treatment on the microtensile bond strength of a dental zirconia ceramic to resin cements. Lasers Med Sci. 2016;31:205-211. doi:10.1007/s10103-015-1848-9

10. Kosmač T, Oblak C, Jevnikar P, Funduk N, Marion L. The effect of surface grinding and sandblasting on flexural strength and reliability of Y-TZP zirconia ceramic. Dent Mater. 1999;15:426-433.

11. Egilmez F, Ergun G, Cekic-Nagas I, Vallittu PK, Lassila LV. Factors affecting the mechanical behavior of Y-TZP. J Mech Behav Biomed Mater. 2014;37:78-87. doi:10.1016/j.jmbbm.2014.05.013

12. Chintapalli RK, Marro FG, Jimenez-Pique E, Anglada M. Phase transformation and subsurface damage in 3YTZP after sandblasting. Dent Mater. 2013;29:566-572. doi:10.1016/j.dental.2013. 03.005

13. Denry I. How and when does fabrication damage adversely affect the clinical performance of ceramic restorations? Dent Mater. 2013;29:85-96. doi:10.1016/j.dental.2012.07.001

14. Aboushelib MN, Kleverlaan CJ, Feilzer AJ. Selective infiltrationetching technique for a strong and durable bond of resin cements to zirconia-based materials. J Prosthet Dent. 2007;98:379-388. doi:10.1016/S0022-3913(07)60123-1

15. Ozcan M, Raadschelders J, Vallittu P, et al. Effect of particle deposition parameters on silica- coating of zirconia using a chairside air-abrasion device. J Adhes Dent. 2013;15:211-214. doi:10.3290/j.jad.a29718

16. Valverde GB, Coelho PG, Janal MN, et al. Surface characterization and bonding of Y-TZP following non-thermal plasma treatment. $J$ Dent. 2013;41:51-59. doi:10.1016/j.jdent.2012.10.002

17. Piascik JR, Swift EJ, Braswell K, Stoner BR. Surface fluorination of zirconia: adhesive bond strength comparison to commercial primers. Dent Mater. 2012;6:604-608. doi:10.1016/j.dental.2012. 01.008

18. Gomes AL, Ramos JC, Santos-Del Riego S, Montero J, Albaladejo A. Thermocycling effect on microshear bond strength to zirconia ceramic using Er: YAG and tribochemical silica coating as surface conditioning. Lasers Med Sci. 2015;2:787-795. doi:10.1007/s10103013-1433-z

19. Liu D, Pow EHN, Tsoi JKH, Matinlinna JP. Evaluation of four surface coating treatments for resin to zirconia bonding. J Mechan Behav Biomed Mater. 2014;32:300-309. doi:10.1016/j.jmbbm.2013.12.011

20. Matinlinna JP, Lung CYK, Tsoi JKH. Silane adhesion mechanism in dental applications and surface treatments: a review. Dent Mater. 2018;34:13-28. doi:10.1016/j.dental.2017.09.002

21. Pott PC, Stiesch M, Eisenburger M. Influence of artificial aging on the shear bond strength of zirconia-composite interfaces after pretreatment with new 10-MDP adhesive systems. J Dent Mater Tech. 2016;5:1-9.

22. Kern M, Barloi A, Yang B. Surface conditioning influences zirconia ceramic bonding. J Dent Res. 2009;88:817-822. doi:10.1177/0022034 509340881

23. Amaral R, Ozcan M, Bottino MA, Valandro LF. Microtensile bond strength of a resin cement to glass infiltrated zirconia-reinforced ceramic: the effect of surface conditioning. Dent Mater. 2006;22:283-290. doi:10.1016/j.dental.2005.04.021

24. Chevalier J. What future for zirconia as a biomaterial? Biomaterials. 2006;27:535-543. doi:10.1016/j.biomaterials.2005.07.034 
25. Aurelio IL, Marchionatti AM, Montagner AF, May LG, Soares FZ. Does air particle abrasion affect the flexural strength and phase transformation of Y-TZP? A systematic review and meta-analysis. Dent Mater. 2016;32:827-845. doi:10.1016/j.dental.2016.03.021

26. Akin H, Ozkurt Z, Kımalı O, Kazazoglu E, Ozdemir AK. Shear bond strength of resin cement to zirconia ceramic after aluminum oxide sandblasting and various laser treatments. Photomed Laser Surg. 2011;29:797-802. doi:10.1089/pho.2011.3039

27. Oyagüe RC, Osorio R, Da Silveira BL, Toledano M. Comparison of bond stability between dual-cure resin cements and pretreated glassinfiltrated alumina ceramics. Photomed Laser Surg. 2011;29:465475. doi:10.1089/pho.2010.2869

28. Paranhos MP, Burnett LH Jr, Magne P. Effect Of Nd: yAGlaser and $\mathrm{CO} 2$ laser treatment on the resin bond strength to zirconia ceramic. Quintessence Int. 2011;42:79-89.

29. Garcõâa-Sanz V, Paredes-Gallardo V, Mendoza-Yero O, et al. The effects of lasers on bond strength to ceramic materials: a systematic review and meta-analysis. PLoS One. 2018;13:e0190736. doi:10.1371/ journal.pone. 0190736

30. D’Amario M, Campidoglio M, Morresi A, Luciani L, Marchetti E, Baldi M. Effect of thermocycling on the bond strength between dualcured resin cements and zirconium-oxide ceramics. J Oral Sci. 2010;52:425-430.

31. Matinlinna JP, Lassila LV, Vallittue PK. The effect of five silane coupling agents on the bond strength of a luting cement to a silicacoated titanium. Dent Mater. 2007;23:1173-1180. doi:10.1016/j. dental.2006.06.052

32. Matinlinna JP, Lassila LV, Vallittue PK. Pilot evaluation of resin composite cement adhesion to zirconia using a novel silane system. Acta Odontol Scand. 2007;65:44-51. doi:10.1080/00016350600973060

33. Tzanakakis EG, Tzoutzas IG, Koidis PT. Is there a potential for durable adhesion to zirconia restorations? A systematic review. $J$ Prosthet Dent. 2016;115:9-19. doi:10.1016/j.prosdent.2015.09.008

34. Cristoforides P, Amaral R, May LG, Bottino MA, Valandro LF. Composite resin to yttria stabilized tetragonal zirconia polycrystal bonding: comparison of repair methods. Oper Dent. 2012;37:263271. doi:10.2341/11-193-L

35. Kirmali O, Kustarci A, Kapdan A, Er K. Efficacy of surface roughness and bond strength of Y-TZP zirconia after various Pre-Treatments Photomed Laser Surg. 2015;33:15-21. doi:10.1089/pho.2014.3825

36. Nahas P, Zeinoun T, Namour M, Ayach T, Nammour S. Effect of Er: yAGlaser energy densities on thermally affected dentin layer: morphological study. Laser Ther. 2018;27:91-97. doi:10.5978/islsm.18OR-07

37. Mirmohammadi H, Aboushelib MN, Salameh Z, Kleverlaan CJ, Feilzer AJ. Influence of enzymatic and chemical degradation on zirconia resin bond strength after different surface treatments. Am J Dent. 2010;23:327-330.

38. El-Korashy DI, El-Refai DA. Mechanical properties and bonding potential of partially stabilized zirconia treated with different chemo mechanical treatments. $J$ Adhes Dent. 2014;16:365-376. doi:10.3290/ j.jad.a32069

39. Ozcan M, Nijhuis H, Valandro LF. Effect of various surface conditioning methods on the adhesion of dual-cure resin cement with MDP functional monomer to zirconia after thermal aging. Dent Mater J. 2008;27:99-104.

40. Yi YA, Ahn JS, Park YJ, et al. The effect of sandblasting and different primers on shear bond strength between yttria tetragonal zirconia polycrystal ceramic and a self-adhesive resin cement. Oper Dent. 2015;40:63-71. doi:10.2341/13-149-L

41. Amaral M, Belli R, Cesar PF, Valandro LF, Petschelt A, Lohbauer U. The potential of novel primers and universal adhesives to bond to zirconia. J Dent. 2014;42:90-98. doi:10.1016/j.jdent.2013.11.004
42. Samimi P, Hasankhani A, Matinlinna JP, Mirmohammadi H. Effect of adhesive resin type for bonding to zirconia using two surface pretreatments. $J$ Adhes Dent. 2015;17:353-359.

43. Pott PC, Stiesch M, Eisenburger M. Influence of 10-MDP adhesive system on shear bond strength of zirconia-composite interfaces. $J$ Dent Mater Tec. 2015;4:117-126.

44. Studart AR, Filser F, Kocher P, Lu“ Thy H, Gauckler LJ. Cyclic fatigue in water of veneer framework composites for all-ceramic dental bridges. Dent Mater. 2007;23:177-185. doi:10.1016/j. dental.2006.01.011

45. Hallmann L, Ulmer P, Lehmann F, et al. Effect of surface modifications on the bond strength of zirconia ceramic with resin cement. Dent Mater. 2016;32:631-639. doi:10.1016/j.dental.2016.02.001

46. Heikkinen TT, Matilinna JP, Vallittu PK, Lassila LV. long term water storage deteriorates bonding of composite resin to alumina and zirconia short communication. Open Dent J. 2013;30:123-125. doi:10.2174/1874210601307010123

47. Qeblawi DM, Muñoz CA, Brewer JD, Monaco EA Jr. The effect of zirconia surface treatment on flexural strength and shear bond strength to a resin cement. J Prosthet Dent. 2010;103:210-220. doi:10.1016/S0022-3913(10)60033-9

48. Atta MO, Smith BGN, Brown D. Bond strengths of three chemical adhesive cements adhered to a nickel chromium alloy for direct bonded retainers. J Prosthet Dent. 1990;63:137-143. doi:10.1016/ 0022-3913(90)90096-u

49. Hummel M, Kern M. Durability of the resin bond strength to the alumina ceramic Procera. Dent Mater. 2004;20:498-508. doi:10.1016/ j.dental.2003.10.014

50. Aboushelib MN, Mirmohamadi H, Matinlinna JP, Kukk E, Ounsi HF, Salameh Z. Innovations in bonding to zirconia-based materials. Part II: focusing on chemical interactions. Dent Mater. 2009;25:989-993. doi:10.1016/j.dental.2009.02.011

51. Oyagüe RC, Monticelli F, Toledano M, Osorio E, Ferrari M, Osorio R. Effect of water aging on microtensile bond strength of dual-cured resin cements to pre-treated sintered zirconium-oxide ceramics. Dent Mater. 2009;25:392-399. doi:10.1016/j.dental.2008.09.002

52. Jaffer F, Finer Y, Santerre JP. Interactions between resin monomers and commercial composite resins with human saliva derived esterases. Biomaterials. 2002;23:1707-1719. doi:10.1016/s0142-9612(01)00298-8

53. Kern M. Bonding to oxide ceramics-laboratory testing versus clinical outcome. Dent Mater. 2014;31:8-14. doi:10.1016/j.dental.2014.06.007

54. Yaman BC, Ozer F, Takeichi T, Karabucak B, Koray F, Blatz MB Effect of thermomechanical aging on bond strength and interface morphology of glass fiber and zirconia posts bonded with a self-etch adhesive and a selfadhesive resin cement to natural teeth. $J$ Prosthet Dent. 2014;112:455-464. doi:10.1016/j.prosdent.2013.11.008

55. Zhang Y, Kim JW. Graded structures for damage resistant and aesthetic all-ceramic restorations. Dent Mater. 2009;25:781-790. doi:10.1016/j.dental.2009.01.002

56. Aboushelib MN, Ragab H, Arnaot M. Ultrastructural analysis and long-term evaluation of composite-zirconia bond strength. $J$ Adhes Dent. 2018;20:33-39. doi:10.3290/j.jad.a39962

57. Valandro LF, Della Bona A, Antonio Bottino M, Neisser MP. The effect of ceramic surface treatment on bonding to densely sintered alumina ceramic. J Prosthet Dent. 2005;93:253-259. doi:10.1016/j. prosdent.2004.12.002

58. Palacios RP, Johnson GH, Phillips KM, Raigrodski AJ. Retention of zirconium oxide ceramic crowns with three types of cement. $J$ Prosthet Dent. 2006;96:104-114. doi:10.1016/j.prosdent.2006.06.001

59. Xie H, Tay FR, Zhang F, Lu Y, Shen S, Chen C. Coupling of 10 methacryloyloxydecyldihydrogenphosphate to tetragonal zirconia: effect of $\mathrm{pH}$ reaction conditions on coordinate bonding. Dent Mater. 2015;31:e218-e225. doi:10.1016/j.dental.2015.06.014 


\section{Publish your work in this journal}

Clinical, Cosmetic and Investigational Dentistry is an international, peer-reviewed, open access, online journal focusing on the latest clinical and experimental research in dentistry with specific emphasis on cosmetic interventions. Innovative developments in dental materials, techniques and devices that improve outcomes and patient satisfaction and preference will be highlighted. The manuscript management system is completely online and includes a very quick and fair peer-review system, which is all easy to use. Visit http://www.dovepress.com/testimonials.php to read real quotes from published authors.

Submit your manuscript here: https://www.dovepress.com/clinical-cosmetic-and-investigational-dentistry-journal 